JPPI Vol 7 No 2 (2017) 87-96

\author{
Jurnal Penelitian Pos dan Informatika \\ 771/AUI/P2MI-LIPI/08/2017 \\ $32 \mathrm{a} / \mathrm{E} / \mathrm{KPT} / 2017$ \\ e-ISSN 2476-9266 \\ p-ISSN: 2088-9402 \\ DOI: 10.17933/jppi.2017.070201
}

\title{
PENERAPAN ALGORITMA APRIORI TID SEBAGAI METODE OPTIMASI PENCARIAN DATA PADA APLIKASI MOBILE SIDOARJO on HANDS (SoH)
}

\section{SEARCHING OPTIMIZATION IN SIDOARJO ON HANDS (SOH) MOBILE APPLICATION USING APRIORI TID ALGORITHM}

\author{
Rani Purbaningtyas ${ }^{1}$, Arif Arizal ${ }^{2}$, Tri Wardoyo ${ }^{3}$ \\ 1,2 Prodi Informatika Fakultas Teknik (Universitas Bhayangkara Surabaya) \\ ${ }^{3}$ Prodi Teknik Sipil Fakultas Teknik (Universitas Bhayangkara Surabaya) \\ 1,2,3 Jl. Ahmad Yani no. 114 Surabaya Telp. 031-8285602, Fax. 031-8285601 \\ raniubhara@gmail.com
}

Naskah Diterima: 15 Agustus 2017; Direvisi : 12 September 2017; Disetujui : 12 September 2017

\begin{abstract}
Abstrak
SoH merupakan aplikasi mobile berbasis android yang dapat memudahkan masyarakat untuk mendapatkan informasi tentang potensi daerah yang dimiliki Kabupaten Sidoarjo. SoH dikembangkan dengan tujuan agar dapat mendukung promosi potensi daerah Kabupaten Sidoarjo. Pencarian data pada prototype aplikasi SoH versi 1.0 menggunakan metode join matching query. Sistem sudah mampu menampilkan hasil pencarian potensi Kabupaten Sidaorjo dengan baik namun dirasa kurang optimal. Agar pencarian data oleh sistem dapat lebih optimal maka digunakan algoritma Apriori TID. Algoritma TID digunakan untuk retrieve data pada riwayat penggunaan aplikasi SoH yang tersimpan dalam sistem. Proses retrieve data akan menghasilkan rekomendasi pencarian data potensi daerah Kabupaten Sidoarjo. Hasil rekomendasi ini akan digunakan oleh sistem untuk melakukan pencarian data pada server data potensi Kabupaten Sidoarjo. Dengan menerapkan algoritma Apriori TID pada saat pencarian data potensi Kabupaten Sidoarjo, hasil pencarian dapat lebih optimal. Hal ini disebabkan karena pencarian data oleh engine system dilakukan dengan menggabungkan 2 pihak secara bersamaan, yaitu server data potensi Kabupaten Sidoarjo dan server data riwayat penggunaan aplikasi SoH oleh pengguna $\mathrm{SoH}$ itu sendiri.
\end{abstract}

Kata kunci: Apriori TID, pencarian data, Sidoarjo

\section{Abstract}

SoH is android based mobile application. SoH ease people to get information about the local potential of Sidoarjo. SoH is aimed to support promotion of the local potential of Sidoarjo. Data searching in the prototype of SoH version 1.0 implements join matching query method. System can show appropriate searching result of the local potential of Sidoarjo but it seems less optimum. To increase efficiency of data searching, we implement Apriori TID algorithm. Apriori TID algorithm is used to retrieve data from history of SoH usage. This process produces recommendation of the local potential of Sidoarjo. By implementing Apriori TID algorithm the result of data searching become more optimum. It is possible because data searching which was done by engine system combine server of Sidoarjo potential and server of history of SoH usage itself.

Keywords: Apriori TID, data searching, Sidoarjo 


\section{PENDAHULUAN}

Aplikasi mobile Sidoarjo on Hands (SoH) merupakan aplikasi mobile berbasis android yang dapat memudahkan masyarakat untuk mendapatkan informasi tentang potensi daerah yang dimiliki Kabupaten Sidoarjo. SoH dikembangkan dengan tujuan agar dapat mendukung promosi potensi daerah Kabupaten Sidoarjo. Semua informasi mengenai potensi daerah yang dimiliki oleh Kabupaten Sidoarjo meliputi potensi industri, potensi pertanian, potensi perikanan, potensi kerajinan, potensi wisata hingga potensi kuliner dapat dengan mudah diketahui oleh masyarakat melalui aplikasi ini. Sehingga masyarakat lokal maupun masyarakat luar yang ingin mengenal lebih dekat tentang Kabupaten Sidoarjo dapat memperoleh informasi yang dibutuhkan melalui SoH.

Pada pengembangan prototype SoH versi 1.0 sebelumnya (Purbaningtyas dkk, 2017) proses pencarian data oleh pengguna $\mathrm{SoH}$ dilakukan dengan menerapkan metode join matching query. Join matching query merupakan metode yang menggabungkan pencarian data teks pada server data potensi daerah Sidoarjo dengan data peta pada server data spasial. Sebenarnya, dengan menerapkan metode join matching query ini, pengguna $\mathrm{SoH}$ sudah bisa mendapatkan informasi tentang potensi daerah Kabupaten Sidoarjo yang dicari. Namun, metode join matching query dirasa kurang optimal dari sisi kesesuaian informasi yang ditampilkan terhadap kebutuhan pengguna $\mathrm{SoH}$. Hasil pencarian yang ditampilkan tidak jarang kurang bisa memenuhi kebutuhan pengguna $\mathrm{SoH}$ versi sebelumnya.
Berdasarkan hasil evaluasi pada tahap analisis dan pengembangan sistem sebelumnya, akan dirasa lebih bermanfaat jika aplikasi SoH tidak hanya mampu memberikan informasi sesuai dengan yang dicari oleh pengguna saja. Diharapkan, aplikasi SoH dapat memberikan rekomendasi hasil pencarian informasi potensi Kabupaten Sidoarjo yang disesuaikan dengan riwayat penggunaan aplikasi SoH oleh pengguna tersebut. Dengan banyaknya data yang terdapat pada riwayat penggunaan $\mathrm{SoH}$ oleh pengguna, pencarian pada data riwayat ini dirasa perlu dioptimalkan. Tujuannya untuk mendapatkan hasil yang optimal pada saat melakukan query (Ermatita, 2009). Salah satu metode yang dirasa mampu menyelesaikan permasalahan ini yaitu algoritma Apriori (Astuti, dkk 2016), khususnya Apriori TID.

Algoritma Apriori TID merupakan salah satu algoritma association rules. Association rules bertujuan untuk mencari sekelompok item (itemsets) yang memiliki nilai support yang lebih besar daripada minimum support yang ditentukan dan menggunakan sekelompok besar itemsets untuk membangkitkan aturan yang memiliki nilai confidence lebih besar daripada nilai minimum confidence yang ditetapkan. Tujuannya adalah menentukan rasio dari nilai support item yang dicari terhadap nilai item lainnya pada saat tidak saling tergantung satu sama lain (R Agrawal.,et,al, 1994)

Dengan menerapkan algoritma Apriori TID pada saat pencarian data, rekomendasi keluaran $\mathrm{SoH}$ yang dihasilkan akan melihat hubungan antara potensi yang dicari saat ini terhadap riwayat pencarian potensi daerah Kabupaten Sidorajo pada saat penggunaan aplikasi SoH periode sebelumnya. Berdasarkan penjelasan diatas, maka artikel penelitian ini membahas bagaimana penerapan 
algoritma Apriori TID untuk mengoptimalkan proses pencarian informasi tentang potensi Kabupaten Sidoarjo yang terdapat pada aplikasi SoH.

\section{METODE}

Metode penelitian yang diterapkan dalam mengembangkan $\mathrm{SoH}$ sendiri menggunakan model waterfall yang terdiri dari tahapan definisi dan analisis kebutuhan sistem, perancangan desain sistem, pengembangan, pengujian dan implementasi sistem.

Definisi dan analisis kebutuhan sistem dilakukan melalui pengambilan data primer dan sekunder. Data primer didapat dari para pelaku industri secara langsung. Data sekunder didapat dari dinas_dan instansi yang terkait dengan masing-masing kelompok potensi yang ada. Potensi daerah yang dimiliki Kabupaten Sidoarjo terbagi menjadi 6 kelompok potensi utama yaitu-: potensi industri, potensi pertanian, potensi perikanan, potensi kerajinan, potensi wisata hingga potensi kuliner.

Perancangan desain sistem menggunakan pendekatan analisis dan desain sistem terstruktur. Analisis data khususnya yang digunakan untuk pencarian informasi potensi Kabupaten Sidoarjo menerapkan algoritma Apriori TID. Algoritma Apriori TID akan membaca pola pencarian informasi yang dibutuhkan pengguna berdasarkan riwayat penggunaan aplikasi $\mathrm{SoH}$ yang dilakukan oleh pengguna itu sendiri.

Algoritma Apriori TID merupakan salah satu bagian dari association rule mining. Association rule mining merupakan salah satu teknik yang ada dalam penambangan data yang bertujuan untuk mendapatkan aturan asosiasi atau relasi antara sekumpulan item. Aturan asosiasi dapat diperoleh dari berbagai sumber data, di antaranya berasal dari basis data transaksional, gudang data, maupun dari tempat penyimpanan informasi yang lainnya. Pada umumnya data yang diolah bersifat homogen. Studi pertama tentang pencarian aturan asosiasi diperoleh dari itemset yang sering muncul secara bersamasama (R Agrawal.,et,al, 1993). Salah satu algoritma yang sering digunakan untuk pencarian aturan asosiasi adalah Apriori (Gunawan, dkk, 2016). Penting tidaknya sebuah aturan asosiasi dapat diketahui dengan dua parameter, yaitu support (nilai penunjang), yaitu persentase kejadian kombinasi item atau support count jumlah itemset yang muncul dalam sekumpulkan transaksi, dan confidence (nilai kepastian), yaitu kuatnya hubungan antar item dalam aturan asosiasi (J. Han., et,al, 2012)

Analisis asosiasi didefinisikan suatu proses untuk menemukan semua aturan assosiatif yang memenuhi syarat minimum untuk support (minimum support), dan syarat minimum untuk confidence (minimum confidence). Secara umum, aturan asosiasi (Arizal, 2012) diperoleh dengan cara sebagai berikut: Misalnya terdapat $\mathrm{I}=\left\{\mathrm{i}_{1}, \mathrm{i}_{2}, \mathrm{i}_{3}, \ldots \mathrm{i}_{\mathrm{n}}\right\}$ yang merupakan sekumpulan item, sementara D adalah sekumpulan transaksi, di mana setiap transaksi $\mathrm{T}$ memiliki sekumpulan item di mana $T \subseteq I$. Setiap transaksi akan memiliki TID (Transaction IDentifier) yang unik. Setiap transaksi dikatakan mengandung $\mathrm{X}$, kumpulan item dalam I, jika $X \subseteq T$. Sebuah aturan asosiasi diformulasi dengan bentuk $X \rightarrow Y$, dimana $X \subseteq I ; Y \subseteq I$; dan $X \cap Y=\Phi$. Aturan $X \rightarrow Y$ memiliki support $\mathrm{s}$ dalam transaksi D jika s\% atau jumlah s dari transaksi dalam D mengandung $X \cup Y$. Atau dengan kata lain, support dari suatu aturan adalah 
probabilitas kejadian X dan Y secara bersama-sama atau jumlah kejadian $\mathrm{X}$ dan $\mathrm{Y}$ secara bersama. Aturan $X \rightarrow Y$ memiliki nilai confidence c jika c\% dari transaksi D mengandung $\mathrm{X}$ juga mengandung Y. Atau dengan kata lain, confidence dari sebuah aturan adalah probabilitas kondisional dengan konsekuen $\mathrm{Y}$ adalah benar, jika $\mathrm{X}$ merupakan antisedennya. Support adalah probabilitas dari item atau sekumpulan item dalam sebuah basis data transaksional seperti pada (1).

$$
\text { Support }(X)=\frac{n(X)}{n}
$$

dimana $\mathrm{n}$ adalah jumlah total transaksi dalam basis data, sedangkan $\mathrm{n}_{-}(\mathrm{X})$ adalah jumlah transaksi yang mengandung itemset $\mathrm{X}$, atau support count yaitu jumlah item yang terdapat dalam transaksi. Confidence adalah probabilitas kondisional, untuk aturan asosiasi $X \rightarrow Y$ didefinisikan seperti pada (2).

$$
\text { Confidence }(X \rightarrow \mathrm{Y})=\frac{\text { Support }(x \cup Y)}{\text { Support }(X)}
$$

Untuk mengukur tingkat akurasi dari sebuah aturan yang diperoleh, digunakan rumusan Lift
Ratio. Lift Ratio dari aturan $X \rightarrow Y$ didefinisikan seperti pada (3).

$$
\text { Lift Ratio }(X \rightarrow Y)=\frac{\text { Confidence }(X \rightarrow Y)}{\text { Expected Confidence }(X \rightarrow Y)}
$$

di_mana Expected Confidence didefinisikan seperti pada (4).

$$
\text { Expected Confidence }(X \rightarrow Y)=\frac{\operatorname{Support}(Y)}{\text { Support }(X \cup Y)}
$$

Jika nilai lift ratio $>1$, aturan $X \rightarrow Y$ muncul lebih sering dari yang diharapkan,_-maka $\mathrm{X}$ dan $\mathrm{Y}$ tidak saling bergantung (independent). Jika lift ratio $=1$, maka aturan $X \rightarrow Y$ muncul sesuai dengan yang diharapkan. Tetapi jika lift ratio $<1$, maka aturan $X \rightarrow Y$ muncul lebih jarang dari yang diharapkan dan X, Y saling bergantung (dependent).

Langkah-langkah penyelesaian yang diambil untuk menerapkan algoritma Apriori TID pada tahapan pencarian informasi potensi daerah Kabupaten Sidoarjo pada aplikasi SoH tercantum pada gambar 1 sebagai berikut :

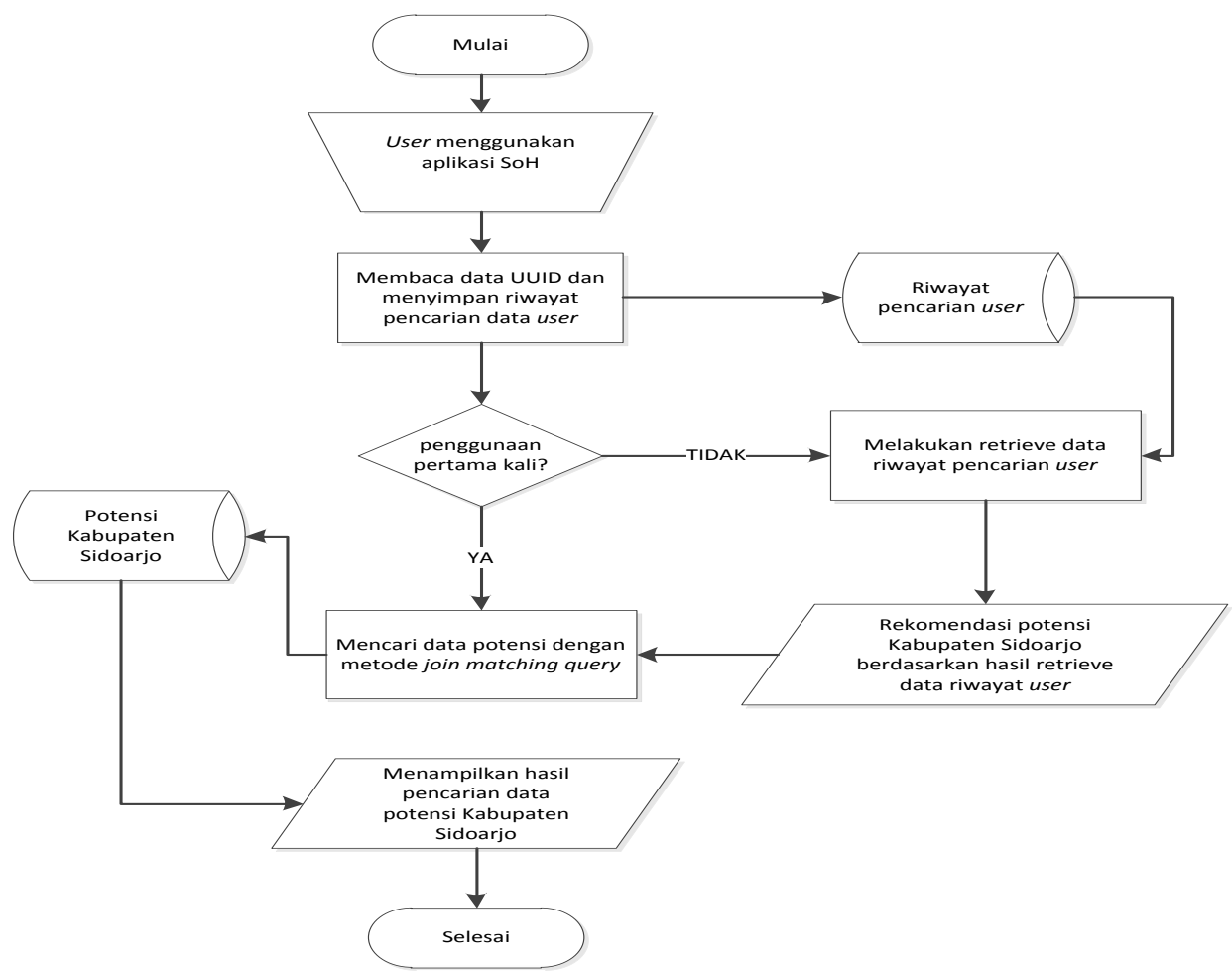

Gambar 1. Alur pencarian data potensi Kabupaten Sidoarjo pada aplikasi SoH 
1. Setiap kali pengguna SoH memanfaatkan aplikasi SoH, maka sistem akan membaca data UUID dari pengguna $\mathrm{SoH}$ tersebut dan menyimpan riwayat pencarian data yang dilakukan oleh pengguna tersebut. Nantinya, sistem akan melakukan pencarian data kedalam server SoH dengan menggunakan UUID dari pengguna SoH tersebut sebagai kunci pencarian data.

2. Jika pengguna tersebut baru pertama kali menggunakan aplikasi SoH, maka pencarian data potensi Kabupaten Sidoarjo akan dilakukan dengan menggunakan metode join matching query.

3. Jika pengguna tersebut sudah beberapa kali menggunakan aplikasi SoH, maka sistem akan melakukan proses retrieve data menggunakan algoritma Apriori TID untuk membaca riwayat penggunaan aplikasi SoH. Berdasarakan riwayat penggunaan aplikasi SoH tersebut, maka sistem akan memberikan rekomendasi data potensi

Kabupaten Sidoarjo sesuai riwayat pengguna.
4. Hasil rekomendasi data tersebut akan digunakan oleh sistem untuk melakukan pencarian data potensi Kabupaten Sidoarjo dalam server $\mathrm{SoH}$.

5. Sistem akan menampilkan informasi potensi Kabupaten Sidoarjo yang dibutuhkan oleh pengguna $\mathrm{SoH}$.

Pada aplikasi SoH versi 1.0 pencarian data menggabungkan antara pencarian data teks pada server data potensi daerah Sidoarjo dengan data peta pada server data spasial. Dengan diterapkannya algoritma Apriori TID pada $\mathrm{SoH}$ versi 2.0, rancangan basis data pada $\mathrm{SoH}$ versi 1.0 perlu diperbaiki. Hal ini disebabkan karena belum adanya tabel yang bisa digunakan untuk menyimpan riwayat penggunaan $\mathrm{SoH}$ oleh pengguna. Sementara algoritma Apriori TID membutuhkan data tersebut sebagai dasar menghasilkan rekomendasi potensi daerah yang dimiliki Kabupaten Sidoarjo. Berikut adalah rancangan basis data pada $\mathrm{SoH}$ versi 2.0 yang telah diperbarui seperti tampak pada gambar 2 berikut ini :

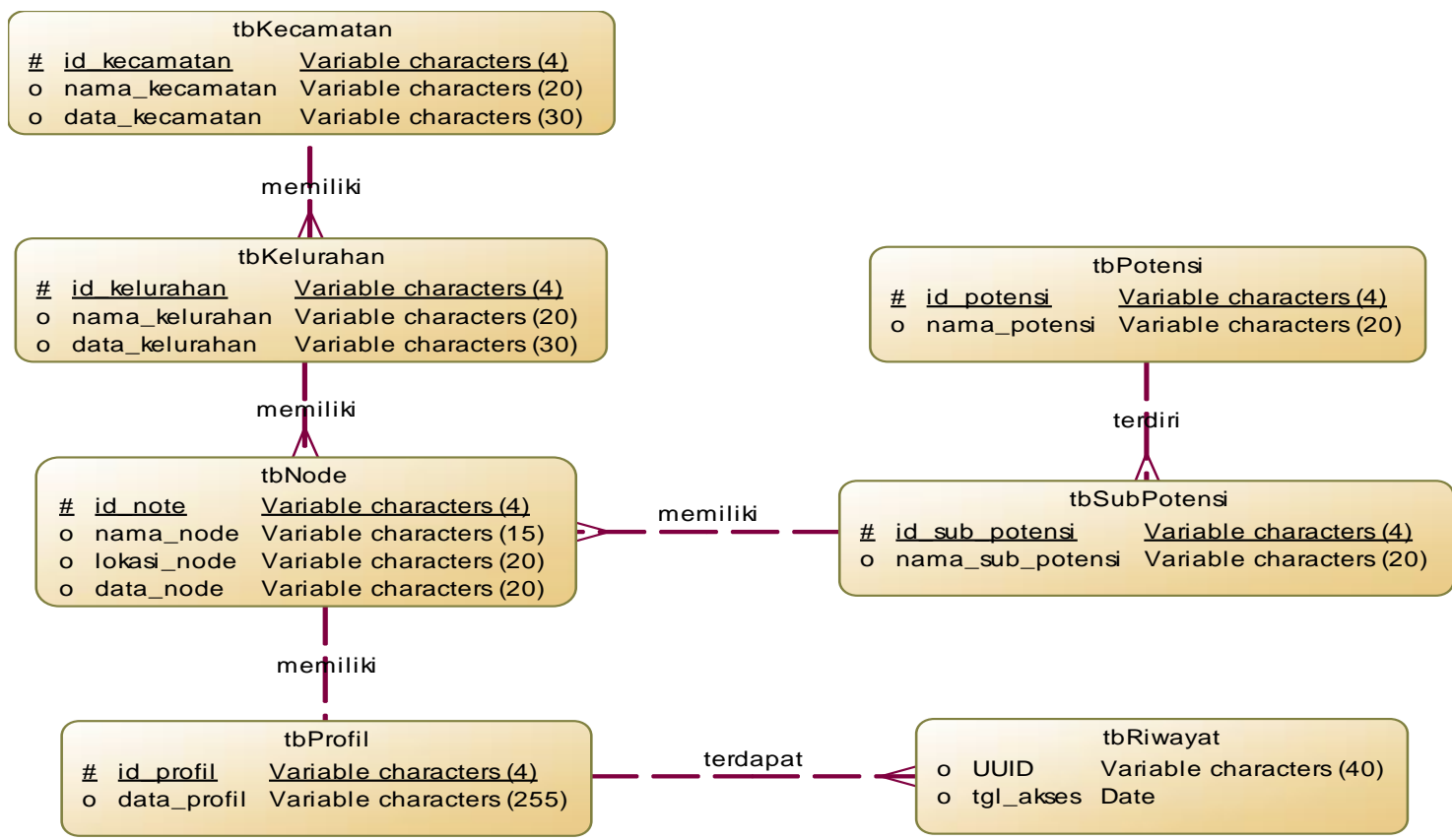

Gambar 2. Rancangan basis data pada SoH versi 2.0 
Fungsi dari dari masing-masing tabel diatas adalah sebagai berikut :

1. Tabel kecamatan, digunakan untuk menyimpan data-data 18 kecamatan yang ada di Kabupaten Sidoarjo. 18 kecamatan tersebut yaitu : Balongbendo, Buduran, Candi, Gedangan, Jabon, Krembung, Krian, Porong, Prambon, Sedati, Sidoarjo, Sukodono, Taman, Tanggulangin, Tarik, Tulangan, Waru dan Wonoayu (Pemkab Sidoarjo, 2015).

2. Tabel kelurahan, digunakan untuk menyimpan data-data kelurahan yang ada di setiap kecamatan. Total jumlah kelurahan di Sidoarjo yaitu 322 desa (BPS Kabupaten Sidoarjo, 2015).

3. Tabel potensi, digunakan untuk menyimpan data klasifikasi potensi daerah yang dimiliki Kabupaten Sidoarjo. Kelompok potensi utama tersebut yaitu industri, pertanian, perikanan, kerajinan, pariwisata dan kuliner (BPS Kabupaten Sidoarjo, 2015)

4. Tabel sub potensi, digunakan untuk menyimpan data klasifikasi sub potensi daerah dari tiap kelompok potensi utama. Untuk kategori potensi industri terbagi menjadi 3 sub kategori yaitu indutri peralatan rumah tangga, industri knalpot dan industri pande besi. Untuk kategori potensi kerajinan terbagi menjadi 6 sub kategori potensi yaitu tas dan koper, border, batik, konveksi, topi dan sandal. Kategori potensi pariwisata terbagi menjadi sub kategori potensi pariwisata alam dan sub kategori potensi pariwisata buatan. Sedangkan untuk kategori potensi kuliner terbagi menjadi 7 sub kategori potensi kuliner yaitu kerupuk, tahu, tempe, telur asin, petis, nugget, sosis.

5. Tabel node, digunakan menyimpan titik lokasi daerah yang memiliki potensi daerah tertentu.
6. Tabel profil, digunakan untuk menyimpan data pendukung dari setiap titik lokasi yang memiliki potensi daerah tertentu. Profil setiap potensi yang akan ditampilkan nantinya meliputi nama perusahaan, alamat usaha, contact person dari perusahaan tersebut, deskripsi tentang usaha yang dijalankan serta kelebihan dari setiap potensi tersebut.

7. Tabel riwayat, digunakan untuk menyimpan data-data penggunaan $\mathrm{SoH}$ oleh setiap pengguna.

\section{HASIL DAN PEMBAHASAN}

Sebagai contoh, pada saat menggunakan aplikasi SoH saat ini, pengguna mencari potensi "Bordir di kawasan Tanggulangin”. Pada saat pencarian data, sistem akan membaca riwayat penggunaan $\mathrm{SoH}$ pengguna tersebut. Sebagai contoh, riwayat penggunaan $\mathrm{SoH}$ pengguna adalah sebagai berikut:

\begin{tabular}{|c|c|}
\hline TID & Items \\
\hline P001 & 134 \\
\hline P002 & 235 \\
\hline P003 & 1235 \\
\hline P004 & 25 \\
\hline
\end{tabular}

dimana :

$1=$ Batik Wahyu

$2=$ CV. Kurnia

$3=$ UD. Barokah

$4=$ Batik Kharisma

$5=$ Batik Suryono

Items disini merupakan daftar obyek potensi yang ada di Kabupaten Sidoarjo yang pernah dicari oleh pengguna pada masa pencarian sebelumnya. Kemudian ditentukan nilai minimum support. Nilai support disini adalah nilai dukungan dari unit potensi yang ada terhadap keseluruhan data riwayat pencarian potensi yang pernah dilakukan oleh pengguna. 
Nilai minimum support yang digunakan adalah $50 \%$. Kemudian dihitung nilai support untuk masing-masing itemset terhadap keseluruhan data riwayat pengguna dengan hasil sebagai berikut :

Tabel 2. Hasil perhitungan nilai support untuk

\begin{tabular}{cc}
\multicolumn{2}{c}{ satu itemsets } \\
\hline Itemset & Support \\
\hline$\{1\}$ & 2 \\
$\{2\}$ & 3 \\
$\{3\}$ & 3 \\
$\{5\}$ & 3 \\
\hline
\end{tabular}

Dari setiap kelompok itemset pertama pada tabel 2, akan dihitung nilai support dan confidence. Confidence disini berarti mencari tingkat kedekatan atau keterkaitan antara suatu item terhadap item lainnya. Sehingga terbentuk itemset kedua seperti terlihat tabel 3 .

Tabel 3. Pembentukan itemset kedua

\begin{tabular}{ll}
\hline TID & \multicolumn{1}{c}{ Items } \\
\hline P001 & $\left\{\begin{array}{ll}1 & 3\end{array}\right\}$ \\
P002 & $\{23\}\{25\}\left\{\begin{array}{ll}2 & 3\end{array}\right\}$ \\
P003 & $\{12\}\{13\}\{15\}\{23\}\{25\}\{35\}$ \\
P004 & $\{25\}$ \\
\hline
\end{tabular}

Untuk setiap kelompok itemset kedua akan dihitung kembali nilai support sehingga didapatkan hasil sebagai berikut :

Tabel 4. Hasil perhitungan nilai support untuk

\begin{tabular}{|c|c|}
\hline Itemset & Support \\
\hline$\left\{\begin{array}{ll}1 & 2\end{array}\right\}$ & 1 \\
\hline$\{13\}^{*}$ & 2 \\
\hline$\{15\}$ & 1 \\
\hline$\{23\} *$ & 2 \\
\hline$\{25\}^{*}$ & 3 \\
\hline$\{35\}^{*}$ & 2 \\
\hline
\end{tabular}

Dari setiap kelompok itemset pertama pada tabel 4, akan dihitung nilai support dan confidence. Sehingga terbentuk itemset ketiga seperti terlihat tabel 5 .

Tabel 5. Pembentukan itemset ketiga

\begin{tabular}{|c|c|}
\hline TID & Items \\
\hline P002 & $\{235\}$ \\
\hline P003 & $\left\{\begin{array}{l}23 \\
3\end{array}\right\}$ \\
\hline
\end{tabular}

Untuk setiap kelompok itemset ketiga akan dihitung kembali nilai support sehingga didapatkan hasil sebagai berikut :

Tabel 6. Hasil perhitungan nilai support untuk tiga itemsets

\begin{tabular}{cc}
\hline Itemset & Support \\
\hline$\{235\}^{*}$ & 2 \\
\hline
\end{tabular}

Berdasarkan hasil perhitungan pada tabel 6 diatas, maka rekomendasi yang dihasilkan oleh sistem pada saat pencarian "Bordir di kawasan Tanggulangin" adalah : CV. Kurnia, UD. Barokah, dan Batik Suryono.

Berikut perbandingan keluaran dari $\mathrm{SoH}$ sebelum dan sesudah implementasi algoritma Apriori TID. Dengan asumsi bahwa pengguna tersebut telah beberapa kali menggunakan $\mathrm{SoH}$. Sebagai contoh, ada seseorang yang ingin melakukan pencarian data tentang potensi kerajinan bordir yang terdapat di Kabupaten Sidoarjo. Jika sistem hanya melakukan proses pencarian data menggunakan metode join matching query saja, maka hasil pencarian sistem adalah sebagai berikut:

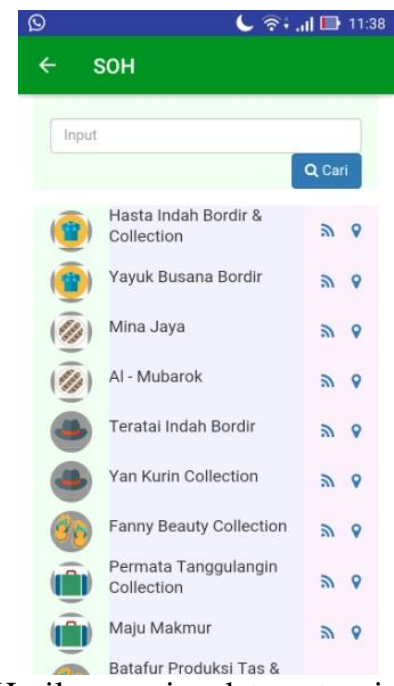

Gambar 4. Hasil pencarian data potensi menggunakan metode join matching query

Pada gambar 4 diatas dapat dilihat bahwa $\mathrm{SoH}$ menampilkan keseluruhan potensi kerajinan bordir 
di kawasan Tanggulangin, Kabupaten Sidoarjo sesuai dengan yang dicari oleh pengguna yaitu "Bordir di kawasan Tanggulangin".

Pada gambar 5, dengan menerapkan algoritma Apriori TID pada saat pencarian data oleh sistem, maka SoH menampilkan hasil pencarian sistem sebagai berikut:

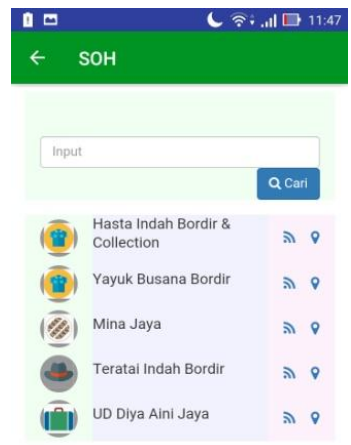

Gambar 5. Hasil pencarian data potensi dengan menerapkan algoritma Apriori TID

Pada gambar 5 di atas dapat dilihat bahwa $\mathrm{SoH}$ tidak hanya menampilkan potensi kerajinan bordir di kawasan Tanggulangin Kabupaten Sidoarjo sesuai dengan yang dicari oleh pengguna yaitu "Bordir di kawasan Tanggulangin". Akan tetapi juga menganalisis riwayat penggunaan aplikasi $\mathrm{SoH}$ oleh pengguna. Sehingga diharapkan informasi yang ditampilkan lebih sesuai dengan kebutuhan pengguna karena disesuaikan dengan kebiasaan pencarian potensi daerah Kabupaten Sidoarjo yang dilakukan oleh pengguna. Kebiasaan pencarian ini tampak dari riwayat penggunaan aplikasi SoH yang dilakukan oleh pengguna.

Dari kedua hasil pencarian oleh sistem tersebut dapat dilihat bahwa pencarian sistem dengan menerapkan algoritma Apriori TID lebih optimal. Hal ini disebabkan karena proses pencarian data tidak hanya menggunakan data yang tersimpan dalan server potensi Kabupaten Sidoarjo saja tetapi digabungkan dengan analisis data riwayat penggunaan aplikasi SoH oleh pengguna $\mathrm{SoH}$.

\section{PENUTUP}

Hasil pencarian data pada prototype aplikasi SoH versi 1.0 yang menggunakan metode join matching query sudah mampu menampilkan hasil pencarian potensi Kabupaten Sidaorjo dengan baik. Namun hasil pencarian data tersebut dirasa kurang optimal karena tidak jarang kurang memenuhi kebutuhan pengguna SoH. Agar pencarian data oleh sistem dapat lebih optimal maka digunakan algoritma Apriori TID. Algoritma TID digunakan untuk retrieve data pada riwayat penggunaan aplikasi SoH yang tersimpan dalam sistem.

Dengan menerapkan algoritma Apriori TID pada saat pencarian data potensi Kabupaten Sidoarjo, hasil pencarian dapat lebih optimal. Hal ini disebabkan karena pencarian data oleh engine system dilakukan dengan menggabungkan 2 pihak secara bersamaan, yaitu server data potensi Kabupaten Sidoarjo dan server data riwayat penggunaan aplikasi $\mathrm{SoH}$ oleh pengguna $\mathrm{SoH}$ itu sendiri.

\section{UCAPAN TERIMA KASIH}

Terima kasih disampaikan kepada para pelaku industri dan UMKM di lingkungan Kabupaten Sidoarjo, Dinas Pemuda Olahraga dan Pariwisata Kabupaten Sidoarjo, Dinas Perindustrian dan Perdagangan Kabupaten Sidoarjo, Dinas Koperasi dan Usaha Mikro Kabupaten Sidoarjo serta DRPM Dirjen Kemenristek Dikti yang telah memberikan dukungan dana sehingga terlaksananya penelitian "Aplikasi Mobile Sidoarjo on Hands (SoH) Sebagai Media Penunjang Promosi Daerah Kabupaten Sidoarjo" melalui skema Penelitian Produk Terapan Tahun 2017. 


\section{DAFTAR PUSTAKA}

Agrawal, R., \& Srikant, R. (1994). Fast Algorithms for Mining Association Rules. In Proceeding of the 20th Int'l Conference on Very Large Databases vol 1215 (pp. 487-499). San Francisco, USA: Morgan Kaufmann Publisher Inc.

Arizal, A. (2012). Penggunaan Data Mining Untuk Mencari Aturan Asosiatif Dari Database Pengobatan Pada Klinik Amanah Kabupaten Sleman Propinsi DIY Dengan Metode Quantitative Association Rules. Universitas Gajah Mada, Yogyakarta.

Astuti, Femi Dwi, W. A. (2016). Optimasi Pemrograman Query Untuk Algoritma Apriori Berbasis Asosiasi Data Mining. Jurnal Riset Sistem Informasi \& Teknik Informatika (JURASIK) , STIKOM Tunas Bangsa, Vol 1(No 1).

Ermatita. (2009). Analisis Optimasi Query Pada Data Mining. Jurnal Sistem Informasi (JSI), Universitas Sriwijaya, Palembang, Vol 1(No 1).
Gunawan, Ridowati, \& Khabib, M. (2016). No Title. Jurnal Nasional Teknik Elektro Dan Teknologi Informasi (JNTETI) , Universitas Gadjah Mada, Jogjakarta, Vol 5(No 3 Agustus).

Han, J., M. Kamber, \& Pei, J. (2012). Data Mining: Concepts and Techniques (Third edit). USA: Waltham, MA: Morgan Kaufmann.

Pemkab Sidoarjo. (2015). Bagian Telekomunikasi dan Informatika Kabupaten Sidoarjo, 2015. Retrieved from www.sidoarjokab.go.id

Purbaningtyas, R., Arizal, A., \& Wardoyo, T. (2017). Analisis dan Perancangan Sistem Sidoarjo on Hands (SoH) Untuk Mendukung Promosi Potensi Daerah Kabupaten Sidoarjo. In Prosiding Seminar Nasional Teknologi dan Informatika (SNATIF) 2017. Kudus: Fakultas Teknik Universitas Muria.

R Agrawal, Imieliński, T., \& Swami, A. (1993). Mining Association Rules Between Sets of Items in Large Databases. ACM SIGMOD Rec, Vol 22(No 2), 207-216.

Sidoarjo, B. K. (2015). Sidoarjo Dalam Angka 2015 . 
